\title{
Morphometric and density comparisons of Bos taurus scapulae as a proxy to human frontal crania
}

\author{
S. C. Taylor ${ }^{1 *}$ (D), N. Hammer 2,3,4,5, J. Zwirner², B. Ondruschka ${ }^{6}$ and D. C. Kieser ${ }^{1}$
}

\begin{abstract}
Background: In the absence of cadaveric tissues, forensic simulation, trauma modelling, and cranial surgical training necessitates a surrogate for the human calvaria. This study investigates the validity of Bos taurus scapulae as a proxy for human frontal bones by comparing the laminar and cancellous bone thickness, as well as the bone mineral density (BMD) of cadaveric frontal bones and adult Bos taurus scapulae.

Results: This study aimed to validate the bovine scapulae as a valid proxy for forensic experiments, which benefit researchers and investigators who need to recreate forensic scenarios where synthetic proxies are found unsuitable due to their non-viscoelastic nature and cadaveric human models are unavailable due to ethical restrictions. Our results identified different total thicknesses of the relative bones, but non-different cortical measurements between human frontal bone and bovine scapulae. The bone mineral density is similar between both groups.

Conclusion: This study has found Bos taurus scapulae to be a suitable proxy for human frontal bones as it has a similar morphology with regard to thickness and structure as well as a comparable density. However, there is a significant difference between the cancellous bone, and therefore, the overall thickness.
\end{abstract}

Keywords: Scapulae, Proxies, Cadaver, Animal, Anatomy

\section{Key Points}

Bone mineral density (BMD) values are similar to human crania.

- Bos taurus scapulae have similar morphological structures to human frontal bones.

- Ethical recreation for surgical practices, gunshot wounds, and forensic applications.

- With the scapulae being derived from the human food chain no ethical approval was deemed necessary.

\footnotetext{
*Correspondence: 22sethtaylor@gmail.com

'Department of Orthopaedics and Musculoskeletal Medicine, University of Otago, Christchurch, New Zealand

Full list of author information is available at the end of the article
}

\section{Introduction}

In an attempt to enhance ballistic, forensic, and surgical human calvarial research with increased restrictions on cadaveric tissue, there has been a global increase in the use of polyurethane sheets as a proxy for human flat bone (Taylor \& Kranioti, 2018). However, due to the non-viscoelastic nature of polyurethane, other proxies for human bone have been required as seen with Sus scrofa (pig) ribs being utilized as flat bone proxies (Kieser et al., 2011). For cranial flat bone assessment Mahoney utilized Equus caballus (horse) scapulae (Mahoney, 2018) and Rickman and Smith used Bos taurus (cow) scapulae in their comprehensive Scanning Electron Microscope (SEM) study (Rickman \& Smith, 2014) because of the many similarities to human crania with large quadruped mammals which are described to have comparable thicknesses to human crania (Smith et al., 2007). These studies were reinforced by a recent study

\section{Springer Open}

( ) The Author(s). 2020 Open Access This article is licensed under a Creative Commons Attribution 4.0 International License, which permits use, sharing, adaptation, distribution and reproduction in any medium or format, as long as you give appropriate credit to the original author(s) and the source, provide a link to the Creative Commons licence, and indicate if changes were made. The images or other third party material in this article are included in the article's Creative Commons licence, unless indicated otherwise in a credit line to the material. If material is not included in the article's Creative Commons licence and your intended use is not permitted by statutory regulation or exceeds the permitted use, you will need to obtain permission directly from the copyright holder. To view a copy of this licence, visit http://creativecommons.org/licenses/by/4.0/. 


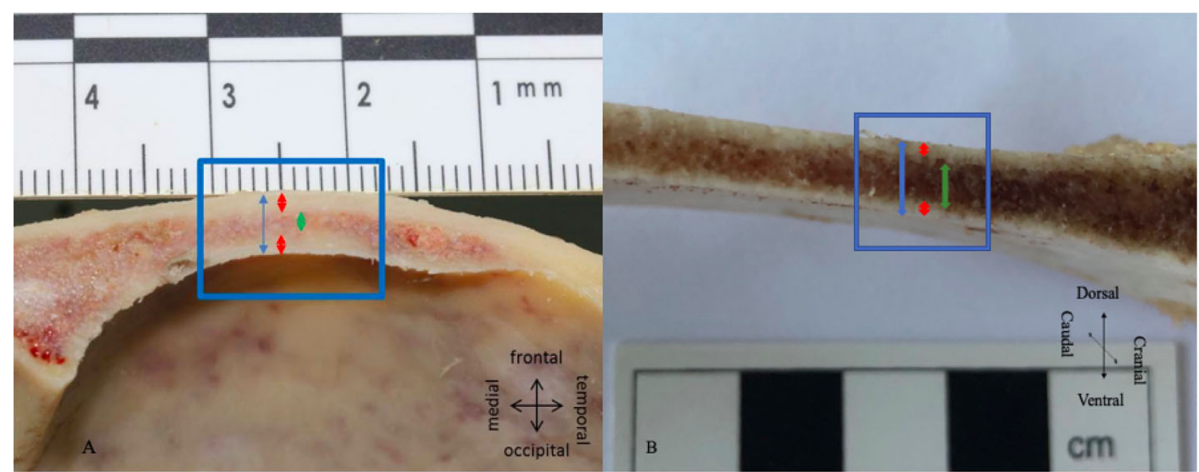

Fig. 1 Representative photograph of a cross-section of human frontal bone (a) and Bos taurus scapulae (b) displaying the area of interest (blue box) and the distances measured: thickness in total (blue arrows), outer and inner cortical layers (red arrows) and cancellous bone (green arrows)

done by Taylor et al. who shot 100 rounds with 6 different calibers into Bos taurus scapulae in order to establish cow scapulae as a valid ballistic proxy for human cranial forensic recreations if the proper area of the scapulae is utilized (Taylor et al., 2020).

Bos taurus scapulae are easy to obtain in large quantities through the human food chain, negating the requirement for ethical approval. However, a paucity of literature exists on the morphometric and density comparison to human flat bones. To date, the only comparisons exist for long bones, with Fletcher et al. identifying that juvenile Bos taurus long bones were a suitable proxy to human long bones with similar densities identified utilizing Computed Tomography (CT) (Fletcher et al., 2018).This study used the areas identified by Taylor et al. as those comparable to human frontal bone thicknesses to assess (Taylor et al., 2020) the validity of an animal model for human bone, the morphological similarity, as well as the bone mineral density (BMD) of Bos taurus scapulae. Therefore, the purpose of this study was to test if Bos taurus scapulae present a suitable morphometric and BMD proxy to human frontal bones.

\section{Materials}

Bos taurus scapulae

Three male steer Bos taurus scapulae aged between 16 and 36 months as per New Zealand butchery standards were acquired from a local butcher (Teara.govt.nz, 2019). Given these tissues were derived from the food chain no ethical approval was deemed necessary. The scapulae were freshly butchered within $48 \mathrm{~h}$ and had been stored a $4{ }^{\circ} \mathrm{C}$. The region of interest was the area of the infraspinatus fossa immediately caudal to the scapular spine (Fig. 2).

\section{Human frontal bones}

Human frontal bones of 8 male and 5 female European cadavers were obtained from a cadaveric collection from the University of Leipzig, Germany. Ethical approval was
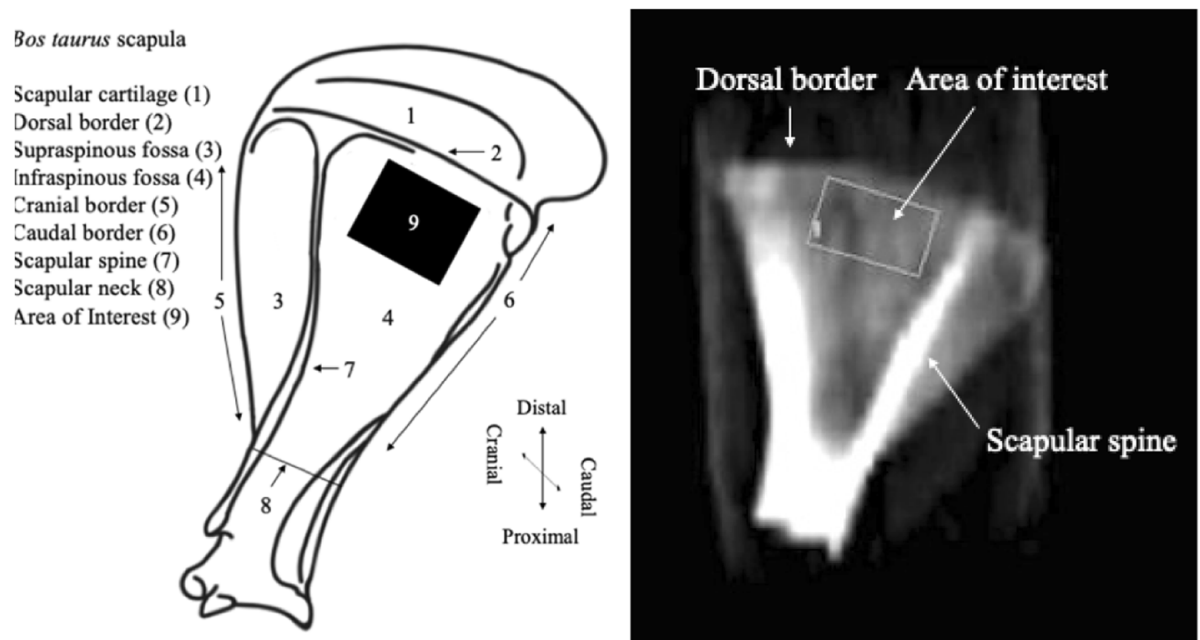

Fig. 2 (Left) Bos taurus scapula. (Right) DXA scan of Bos taurus scapula 
Table 1 Bos Taurus scapulae measurements

\begin{tabular}{llllll}
\hline Scapulae & Age [months] & Thickness Bos taurus scapula & Outer cortical layer & Inner cortical layer & Cancellous bone \\
\hline Average & 27 & $7.3 \mathrm{~mm}$ & $1.9 \mathrm{~mm}$ & $1.6 \mathrm{~mm}$ & $3.5 \mathrm{~mm}$ \\
Standard deviation & 12.7 & $1.1 \mathrm{~mm}$ & $0.4 \mathrm{~mm}$ & $0.3 \mathrm{~mm}$ & $0.6 \mathrm{~mm}$ \\
Minimum & 18 & $5.2 \mathrm{~mm}$ & $1.5 \mathrm{~mm}$ & $1.3 \mathrm{~mm}$ & $2.1 \mathrm{~mm}$ \\
Maximum & 36 & $9.1 \mathrm{~mm}$ & $2.4 \mathrm{~mm}$ & $2.3 \mathrm{~mm}$ & $4.6 \mathrm{~mm}$ \\
\hline
\end{tabular}

obtained by the University of Leipzig Ethics Committee (protocol number 486/16-ek).

\section{Methods}

\section{Previous studies}

The BMD of the bovine scapulae were compared to previous studies of human cranial BMD published by Paschall and Ross (Paschall \& Ross, 2018). These authors used the same method to determine BMD as used in the present study. Paschall and Ross undertook DXA scanning of cranial fragments of human frontal bones in an area of $7.06 \mathrm{~cm}^{2}$ which returned an average BMD value of $0.467 \mathrm{~g} / \mathrm{cm}^{2}$ for the right sided frontal bones and $0.502 \mathrm{~g} / \mathrm{cm}^{2}$ for the left side (Paschall \& Ross, 2018). The overall averaged BMD for both frontal bones was reported as $0.485 \mathrm{~g} / \mathrm{cm}^{2}$. Averaged these results returned a BMD $\left(\mathrm{g} / \mathrm{cm}^{2}\right)$ average of 0.402 , which is considered normal bone density clinically. The Bos taurus scapulae in this study returned a BMD (in $\mathrm{g} / \mathrm{cm}^{2}$ ) of 0.5 which falls into the normal density of human frontal bone. In the clinical setting a DXA scan of $\geq 1.0 \mathrm{~g} / \mathrm{cm}^{2}$ is considered normal ("physiologically") (El Maghraoui \& Roux, 2008).

\section{Bos taurus scapula and human frontal bone measurements}

The overall thickness, inner and outer cortical thickness and the cancellous thickness of each sample was measured with sliding calipers (Fig. 1).

\section{Dual energy X-ray absorptiometry}

DXA scans were performed on a $\mathrm{GE}^{\bullet}$ Lunar Prodigy scanner (GE Healthcare, Madison, WI). Prior to scanning, the machine was calibrated using a GE Lunar DPX-L spine phantom (GE Healthcare, Madison, WI). Due to the removal of soft tissues from the cow bones, a soft-tissue proxy was needed for correct BMD measurements. For this study, white rice served as the soft-tissue proxy. The scapulae were placed in a plastic container on top of the rice (Fig. 2).

The scapulae were scanned using a full body scan and 30 regions of interest (ROI) were analyzed symmetrically through a $10 \times 2 \mathrm{~cm}\left(20 \mathrm{~cm}^{2}\right)$ rectangular "area of interest" just below the spine of the scapula (see Fig. 2). The BMD from each ROI was summed and averaged to provide an average BMD for the area of interest.

\section{IBM SPSS Statistics}

Statistical analysis was carried out using IBM SPSS Statistics Version 25. Normality of the data was checked using Q-Q plots and the Shapiro-Wilks test. One-way ANOVA comparison tests were used to compare the thickness difference between the scapulae and frontal bones for the outer cortical layer, inner cortical layer, and cancellous bone. The non-parametric MannWhitney test was used to compare the overall thickness. $p$ values below 0.05 were deemed significant.

\section{Results}

Scapulae morphological measurements

The results of the measurements on cow scapulae are displayed in Table 1.

\section{Human frontal bone measurements}

The results of the measurements on human frontal bones are displayed in Table 2.

\section{BMD results}

The comparative densities are shown in Table 3.

Table 2 Frontal bone measurements

\begin{tabular}{llllll}
\hline & Age [years] & Thickness human frontal bone $[\mathrm{mm}]$ & Outer cortical layer $[\mathrm{mm}]$ & Inner cortical layer [mm] & Cancellous bone [mm] \\
\hline Average & 36.4 & 5.5 & 1.9 & 1.6 & 2.0 \\
Standard deviation & 7.9 & 1.4 & 0.5 & 0.3 & 1.0 \\
Minimum & 23 & 4.3 & 1.3 & 1.1 & 0.8 \\
Maximum & 50 & 9.8 & 3.0 & 2.3 & 4.5 \\
$p$ value & & $p=0.001$ & $p=0.468$ & $p=0.566$ & $p=0.000$ \\
\hline
\end{tabular}


Table 3 Bone mineral density (BMD) measurements of Bos taurus scapulae and human frontal bones

\begin{tabular}{lll}
\hline & Area $\left(\mathrm{cm}^{2}\right)$ & BMD $\left(\mathrm{g} / \mathrm{cm}^{2}\right)$ \\
\hline Scapulae & 5.0 & 0.4 \\
Frontal bone & 7.1 & 0.5 \\
Standard deviation & 1.5 & 0.1 \\
\hline
\end{tabular}

\section{Statistical results}

All data was distributed normally except the frontal bones overall thickness $(p=0.001)$. There was no significant difference between the outer cortical layer ( $p=$ $0.468)$ and inner cortical layer $(p=0.566)$; however, there was a significant difference between the cancellous bone and the overall thickness $(p<0.001)$.

\section{Discussion}

To our best knowledge, this is the first study to validate the use of Bos taurus scapulae as a proxy for human frontal bone.

The morphometric comparison to the human samples resulted in similar measurements reported by Torimitsu et al. for overall frontal bone thickness $(5-8 \mathrm{~mm})$ (Torimitsu et al., 2015). Moreover, cancellous bone thickness yielded similar results with the study by Lynnerup et al. (Lynnerup et al., 2005). Their material consisted of cranial vault bone biopsies from 43 males (age range 16-90, mean \pm S.D. $=48 \pm 17$ years) and 21 females (age range 23-84 years, mean \pm S.D. $=48 \pm 16$ years) resulting in $2.5 \mathrm{~mm}$ versus the $2.0 \mathrm{~mm}$ from our collection (Lynnerup et al., 2005). Furthermore, the averaged outer cortical layer measurements $(2.4 \mathrm{~mm})$ and inner cortical layer $(1.8 \mathrm{~mm})$ of Lillie et al. are comparable to our forensic cohort which was $1.9 \mathrm{~mm}$ for the outer cortical layer and $1.6 \mathrm{~mm}$ for the inner cortical layer (Lillie et al., 2016).

With gun violence surging worldwide, an ethical bone analog is needed for recreation of gunshot wounds to flat bone (Taylor \& Kranioti, 2018; Kieser et al., 2011; Mahoney, 2018; Rickman \& Smith, 2014; Smith et al., 2007). Other proxies of the human skull are used to approach various research questions and could be used to simulate impacts to the human head in court room, too, helping to recreate crimes and thus are a promising tool from a legal medicine perspective (Brickley \& McKinley, 2004; Ondruschka et al., 2019). Bos taurus scapulae do seem to be an appropriate proxy to human crania for ballistic testing, which can be received from butcheries without the need of sacrificing an animal for this purpose and beyond ethical restrictions and restraints when using human donors and material. The fracture patterns during gunshot experiments obtained from these biological tissues might reflect a more lifelike pattern compared to commercially available polyurethane proxies or own 3D-printed ones based on polylactic acid (Taylor et al., 2020; Zwirner et al., 2017). However, this issue must be proved in the future in detail. Synthetic materials might not reflect the viscoelastic behavior of biological samples in an appropriate manner as they do not fracture with absolute similar patterns due to their nonviscoelastic nature and due to their manufacturing, e.g., the existence of artificial sutures between the model's hemispheres (Taylor \& Kranioti, 2018; Ondruschka et al., 2019).

With measurements of cortical bone returning comparable measurements to human frontal bones and with BMD values similar as well to human crania (Paschall \& Ross, 2018), Bos taurus scapulae seem to be an appropriate proxy for ballistic recreations and also for blunt force analyses or other forensic questions, e.g., preliminary testing of a subsequently larger study cohort, given its economical use in terms of money and disposability (Taylor et al., 2020).

However, there are some limitations with Bos taurus scapulae as a proxy to human crania. Scapulae are flat bones and have no sutures (White et al., 2011) and do not encapsulate an organ with a consistency of the brain to also cover hydraulic burst effects during impact testing (Taylor \& Kranioti, 2018; Kneubuehl, 2011). The effectiveness of the scapulae are limited to entrance and exit wound investigations and small radiating fractures interpretation in ballistic recreations if the appropriate areas of the scapulae are utilized with comparable thicknesses to human crania (5-8 mm) (Rickman \& Smith, 2014; Smith et al., 2007; Taylor et al., 2020). Furthermore, our sample size for this study was small and our results advocate for future testing. Finally, the measurements taken for human bone samples depend on the thickness of the transversal bone cut during autopsy and are further limited to the flat part of the frontal bone.

\section{Conclusions}

In conclusion, this study has found Bos taurus scapulae to be an appropriate proxy to use as it has a similar morphological structure and densities as human frontal bones which can aid in ballistic, forensic, and surgical recreations. Moreover, the use of Bos taurus scapulae are ethically much easier to obtain compared to human cadaveric materials. They pose little to no ethical constraints on researchers looking to recreate surgical practices, gunshot wounds, or forensic recreations on a bone proxy rather than a polyurethane sphere or flat plate, which may fracture differently than bone due to their brittle non-viscoelastic nature.

\section{Abbreviations}

BMD: Bone mineral density; DXA: Dual energy X-ray absorptiometry; SEM: Scanning electron microscope; CT: Computed tomography 


\section{Acknowledgements}

Craig Burton and Pacific Radiology

\section{Authors' contributions}

TSC is the main author as research was undertaken in course with a PhD program. KDC and HN were supervisors and editors. ZJ and OB contributed to the human frontal bone measurements and editing of the manuscript. All authors read and approved the final manuscript.

\section{Funding}

University of Otago.

\section{Availability of data and materials}

Data is available upon request.

\section{Ethics approval and consent to participate}

The Ethics Committee of the University of Leipzig, Germany, approved the use of these tissues for research (protocol number 486/16-ek)

\section{Consent for publication}

Not applicable

\section{Competing interests}

We have no conflicts of interest. All authors have approved the submission.

\section{Author details}

${ }^{1}$ Department of Orthopaedics and Musculoskeletal Medicine, University of Otago, Christchurch, New Zealand. ${ }^{2}$ Department of Anatomy, University of Otago, Dunedin, New Zealand. ${ }^{3}$ Department of Trauma, Orthopedic and Plastic Surgery, University Hospital of Leipzig, Leipzig, Germany. ${ }^{4}$ Fraunhofer Institute for Machine Tools and Forming Technology, Dresden, Germany. ${ }^{5}$ Department of Clinical and Macroscopic Anatomy, Medical University of Graz, Graz, Austria. Institute of Legal Medicine, University of Leipzig, Leipzig, Germany.

Received: 27 March 2020 Accepted: 11 June 2020

Published online: 27 June 2020

\section{References}

Brickley, M. and McKinley, J.I., 2004. Guidelines to the standards for recording human remains. IFA paper, 7. Online available at: https://www.archaeologists. net/sites/default/files/ifa_paper_7.pdf. Accessed: 13 May. 2020

El Maghraoui A, Roux C (2008) DXA scanning in clinical practice. OJM: An International Journal of Medicine 101:605-617

Fletcher JWA, Williams S, Whitehouse MR, Gill HS, Preatoni E (2018) Juvenile bovine bone is an appropriate surrogate for normal and reduced density human bone in biomechanical testing: a validation study. Scientific Reports 8 : 10181

Kieser JA, Tahere J, Agnew C, Kieser DC, Duncan W, Swain MV, Reeves MT (2011) Morphoscopic analysis of experimentally produced bony wounds from lowvelocity ballistic impact. Forensic Science, Medicine, and Pathology 7:322-332

Kneubuehl B.P., 2011. Wound Ballistics: Basics and Applications, Springer-Verlag.

Lillie EM, Urban JE, Lynch SK, Weaver AA, Stitzel JD (2016) Evaluation of skull cortical thickness changes with age and sex from computed tomography scans. Journal of Bone and Mineral Research 31:299-307

Lynnerup N, Astrup JG, Sejrsen B (2005) Thickness of the human cranial diploe in relation to age, sex and general body build. Head \& Face Medicine 1:13

Mahoney, P.F., 2018. Development of a Synthetic Bone and Tissue Model to Simulate Overmatch Military Ballistic Head Injury (Doctoral dissertation Cranfield University). Online available at: https://dspace.lib.cranfield.ac.uk/ handle/1826/13280. Accessed: 13 May. 2020

Ondruschka B, Lee JHC, Scholze M, Zwirner J, Tong D, Waddell JN, Hammer N (2019) A biomechanical comparison between human calvarial bone and a skull simulant considering the role of attached periosteum and dura mater International Journal of Legal Medicine 133:1603-1610

Paschall A, Ross AH (2018) Biological sex variation in bone mineral density in the cranium and femur. Science \& Justice 58:287-291

Rickman JM, Smith MJ (2014) Scanning electron microscope analysis of gunshot defects to bone: an underutilized source of information on ballistic trauma. Journal of Forensic Sciences 59:1473-1486
Smith MJ, Brickley MB, Leassch SL (2007) Experimental evidence for lithic projectile injuries: improving identification of an under-recognised phenomenon. Journal of Archaeological Science 34:540-553

Taylor, S.C., Kieser, D.C., Hammer, N., Ondruschka, B., Hooper, G.J., Kranioti, E.F., 2020. The Viability of Bos taurus Scapulae as a Flat Bone Proxy for Ballistic Testing. BMJ Military Health, doi:10.1136/ jramc-2019-001369.

Taylor SC, Kranioti EF (2018) Cranial trauma in handgun executions: Experimental data using polyurethane proxies. Forensic Science International 282:157-167

Teara.govt.nz. (2019). [online] Available at: https://teara.govt.nz/en/beef-farming/ page-7 [Accessed 18 Jun. 2019].

Torimitsu S, Nishida Y, Takano T, Yajima D, Inokuchi G, Makino Y, Motomura A Chiba F, Yamaguchi R, Hashimoto M, Hoshioka Y (2015) Differences in biomechanical properties and thickness among frontal and parietal bones in a Japanese sample. Forensic Science international 252:190.e1-190.e6

White, T.D., Black, M.T. and Folkens, P.A., 2011. Human osteology. Elsevier Academic press.

Zwirner J, Bayer R, Japes A, Eplinius F, Dreßler J, Ondruschka B (2017) Suicide by the intraoral blast of firecrackers - experimental simulation using a skull simulant model. International Journal of Legal Medicine 131:1581-1587

\section{Publisher's Note}

Springer Nature remains neutral with regard to jurisdictional claims in published maps and institutional affiliations.

\section{Submit your manuscript to a SpringerOpen ${ }^{\circ}$ journal and benefit from:}

- Convenient online submission

- Rigorous peer review

- Open access: articles freely available online

High visibility within the field

- Retaining the copyright to your article

Submit your next manuscript at $\boldsymbol{\nabla}$ springeropen.com 